\title{
A decades-long journey with mobile introns
}

\author{
MARLENE BELFORT \\ Department of Biological Sciences and RNA Institute, State University of New York, Albany, New York 12222, USA
}

Our discovery of introns in phage over 30 years ago propelled me into the RNA arena. That was 10 years before the journal $R N A$ was launched and 70 years since the discovery of phage. The year 2015 is therefore one of celebration for me, the 100th anniversary of phage and 20 years of the journal RNA!

Before we published the phage intron story, Frank Stahl and I struck up a conversation at a phage meeting at Cold Spring Harbor. That was after the discovery of the first of three introns in phage T4, when we were wrestling with a finding that went against the dogma of introns residing exclusively in eukaryotes. With an abundance of caution, I called the intervening sequence a "genetic interruption." Frank said, "Marlene, you must call it an intron before anyone else does." I took his advice, and shortly after, we showed that the "interruption" was a typical group I intron that self-splices by the guanosine-initiated pathway, as defined a few years earlier by the Cech lab. It was a ribozyme, entitling us to full membership in the RNA club.

A few years later, I was invited to serve on the board of the RNA Society (from 1992 to 1996) and on the founding editorial board of the journal RNA. I took my new status seriously and dedicated my lab to the study of introns in bacterial systems; we engaged in understanding intron-based reactions at both the RNA and DNA levels. While much insight was being developed by other labs into group I intron structure and splicing mechanism, we became intrigued by introns as mobile genetic elements, which can efficiently home to unoccupied alleles in DNA. We first elaborated DNA-mediated homing pathways of these group I introns, reactions initiated by intron-encoded endonucleases. Then the homing endonucleases (HEs) became objects of study in themselves, as structurally complex molecules that interact with DNA targets over lengthy stretches. These HEs can adapt to intron function and indeed to that of the host organism. One example is that of the HE chaperoning RNA folding of the intron to assist the splicing process, while another example is of an HE serving as an autorepressor to regulate HE synthesis from the intron RNA.

Much has been written about the evolutionary implications of the discovery of group I introns, and the relationship

\footnotetext{
Corresponding author: mbelfort@albany.edu

Article and publication date are at http://www.rnajournal.org/cgi/doi/10. 1261/rna.050450.115. Freely available online through the RNA Open Access option.
}

of their catalytic RNAs to a primordial RNA world. Their mobility gave rise to more speculation, of how these elements act at the level of the DNA genome to promote its plasticity. There was great excitement about the realization that introns can behave as selfish elements, moving horizontally into genomes, a luxury afforded them by their removal at the RNA level, leaving no trace of their existence in terms of gene expression. Meanwhile, the intron endonucleases spawned an industry in which these enzymes have had success in genome engineering.

Later we became captivated by bacterial group II introns. These too are self-splicing, albeit via the lariat-based pathway of nuclear spliceosomal introns of eukaryotes. Again, while our colleagues determined the details of the self-splicing reaction and the structure of the group II intron ribozyme, we defined their behavior as mobile genetic elements. The group II introns mobilize via RNA-based pathways, in contrast to the DNA-mediated mobility of group I introns. Also, in addition to having solely endonuclease activity, the group II intron-encoded protein is a reverse transcriptase (RT) that promotes retromobility of the intron into DNA targets. The mobility mechanisms of group II introns thus resemble retrotransposons, like LINE elements that populate the human genome. Given their relationship to both nuclear spliceosomal introns and retrotransposons, which collectively occupy more than one-half of the human genome, group II introns are considered by many to have been pivotal elements in the evolution of the metazoan genome.

Group II introns, like group I introns, can integrate efficiently into allelic sites. Because group II introns do so via an RNA intermediate, the process is termed retrohoming. Group II introns can also mobilize into ectopic sites at low frequency. This retrotransposition reaction is thought to be important in an evolutionary time-frame, promoting the spread of introns to new genomic sites. We set about defining the mechanisms of retrohoming and retrotransposition, and the relationship of these pathways to host functions. We thus discovered an arms race between the host and the group II intron, wherein the retroelement exploits cellular functions to proliferate, while being subject to suppression mechanisms meted out by the host.

(C) 2015 Belfort This article, published in RNA, is available under a Creative Commons License (Attribution-NonCommercial 4.0 International), as described at http://creativecommons.org/licenses/by-nc/4.0/. 
The striking similarity between group II and spliceosomal introns in splicing mechanism and structural parallels to the splicesome, down to the $\mathrm{Mg}^{2+}$ binding sites for catalysis, resulted in the widely accepted hypothesis that the catalytic group II intron is the progenitor of the spliceosome and spliceosomal introns. It is speculated that genes encoding autocatalytic group II introns in the ancestral bacterial cell became engulfed in the nuclear genome during eukaryogenesis. Group II introns are posited to have then proliferated within the nucleus and subsequently fragmented into the spliceosome, with its snRNAs that are vestiges of the group II catalytic RNA. One problem with this scenario, however, is that group II introns are notably absent from nuclear genomes. In addressing this conundrum, we have placed group II introns into yeast genes and shown that the intron silences expression of its host gene. We demonstrated that nuclear expression of the group II intron results in cytoplasmic splicing of the pre-mRNA, nonsense-mediated decay and translational repression of the mRNA. These roadblocks are group II intron-specific, with both group I and spliceosomal introns at the same locus being fully consistent with gene expression. Moreover, different group II introns at various loci confer silencing. We have shown that tenacious mRNA-pre-mRNA interactions and pre-mRNA mislocaliza- tion to the cytoplasm result in silencing host gene expression. Although many questions remain to be answered, our data are consistent with the hypothesis that RNA silencing of the host gene contributed to expulsion of group II introns from nuclear genomes and drove the evolution of spliceosomal introns.

There are many captivating questions yet to be answered in the biology of mobile introns. First, it is unknown how group I introns mobilize to ectopic sites. Although transposition has been experimentally demonstrated for group II introns, this is not the case for their group I counterparts. It is, therefore, unknown if lateral dissemination is via a DNA- or RNAbased pathway, the latter via a reverse transcriptase acting in trans. Second, although elegant high-resolution structures exist for both group I and group II intron RNAs, there are none of the introns with their partner proteins, the ribonucleoproteins that facilitate splicing in vivo. Third, we need to establish the structural changes of the group II intron ribonucleoproteins at various stages of RNA splicing, DNA targeting and integration as these dynamic elements mobilize into DNA. Finally, the evolutionary transitions between the group II intron and the spliceosome must be clarified. Answers to these compelling questions are bound to fill the pages of the journal RNA for decades to come. 

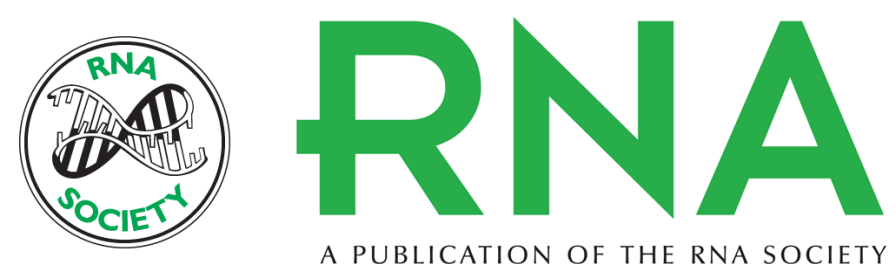

A PUBLICATION OF THE RNA SOCIETY

\section{A decades-long journey with mobile introns}

Marlene Belfort

RNA 2015 21: 567-568

Open Access Freely available online through the RNA Open Access option.

Creative This article, published in RNA, is available under a Creative Commons License

Commons (Attribution-NonCommercial 4.0 International), as described at

License http://creativecommons.org/licenses/by-nc/4.0/.

Email Alerting Receive free email alerts when new articles cite this article - sign up in the box at the Service top right corner of the article or click here. 